\title{
A novel cause for bronchiolitis obliterans organizing pneumonia: exposure to paint aerosols in textile workshops
}

\author{
Ph. Camus*, B. Nemery**
}

In this issue of the Journal, Romero et al. [1] describe 14 patients with severe organizing pneumonia (OP), which resulted from occupational exposure to aerosolized paint in the textile industry in Spain. This spectacular and highly unusual outbreak of occupational lung disease, of which six workers died, took place in the spring of 1992 in the region of Alcoi in the Autonomous Community of Valencia [2]. This highlights the possible emergence of novel lung diseases from inhalation of toxic substances in the industrial setting, and points to an additional aetiological context for bronchiolitis obliterans organizing pneumonia (BOOP), apart from many other causes for this clinicalpathological entity [3-5].

\section{The outbreak of paint-related OP: the "Ardystil syndrome"}

Historically, the first international alert on paint-induced BOOP appeared in 1993 from WickMAN [6], the then correspondent for the British Medical Journal in Spain. According to that report, lung donors were needed to provide transplants for over 10 workers poisoned by paint fumes in Valencian factories [6]. Most cases had occurred in the Ardystil plant in Alcoy, Spain, hence the name for the disease: the Ardystil syndrome. That same year, six of the patients with paint-induced BOOP were briefly reported on by SANZ and PRAT [7], who hypothesized that chan-ges in the formulation of dyes used in the composition of the paint may be causative. The whole series of cases appeared in a now classic paper by MoYa et al. [2], who described an epidemiological investigation conducted in a workforce of 257 persons, mostly young people. Seventy one of these 257 patients had respiratory symptoms, and 22 were defined as having OP on the basis of radiology and histopathology. The overall attack rate was $8.9 \%$ (range 3.6-27.1\%). After 1 yr, 59 workers (83\%) had recovered or were stable, while 12 had deteriorated, of whom six died of uncontrollable OP [2]. Poor hygiene standards were noted in the factories, with a dense mist of paint present in the workshops. The time from first exposure to

\footnotetext{
*Service de Pneumologie et de Réanimation Respiratoire, and Laboratory of Pulmonary Pharmacology and Toxicology, CHU and Université de Bourgogne, Dijon, France. **K.U. Leuven, Laboratorium voor Pneumologie, Leuven, Belgium.
}

Correspondence: P Camus, Service de Pneumologie et de Réanimation Respiratorie and Laboratory of Pulmonary Pharmacology and Toxicology, CHU and Université de Bourgogne, Box 1542, 21034 Dijon, France. Fax: 0033380293625

B. Nemery is holder of "Dr P. Tuytens Leerstoel in Toxicologie". the paint to onset of pulmonary problems could be as short as 1 month [2]. Inquiry and legal investigation suggested that the outbreak was linked to a change in the paint formulation. Indeed, Acramin FWR powder was changed to the liquid Acramin FWN. The change had taken place in 1991, and was almost entirely restricted to the two factories where workers fell ill. Of note, textile air spraying had been carried out earlier with various paints in different factories, with no adverse effects.

Shortly after the Spanish episode, a similar, though smaller (five cases; one death), and less well-documented outbreak developed in Algeria [8]. Although no histology of the lung was available in any of the latter cases, the disease closely resembled that described by MoYa et al. [2]. Importantly, the Algerian workers (mostly women), had used the same paint preparation, applied in a similar fashion, with an aerograph air gun. The paint had been supplied by a Spanish salesperson, and was also thought to be Acramin FWN [8].

\section{Recent outbreaks of gas-, fume- and mist-induced lung disease}

Acute exposure to industrial airborne agents has long been linked to the development of a variety of respiratory problems. Examples of such agents include chlorine, phosgene, oxides of nitrogen, sulphur dioxide, ammonia, hydrogen sulphide, fumes from welding or of heated metals and fire smoke [9-17]. Immediately upon, or within hours after, exposure, the inhalation of gases or fumes can lead to chest discomfort with or without pulmonary oedema [9, 13]. While, in most instances, no long-term sequelae are observed following intoxication, obliterative bronchiolitis with obstruction to airflow, the reactive airway dysfunction syndrome, bronchiectasis, emphysema, or fibrosis may occasionally ensue [13, 18-22].

In addition to the patients described by Moya et al. [2] and ROMERo et al. [1]; other recent and unexpected outbreaks of lung disease have been reported following exposure to inhaled domestic, or occupational agents: 1) An epidemic concerned the inhalation of domestic sprays, with transient, and sometimes severe, pulmonary infiltrates or oedema [23, 24]. Interestingly, most of these cases were reported after the reformulation of sprays, which was required to eliminate 1,1,1-trichloroethane (an ozone-depleting agent), in order to comply with the 1990 amendment to the Clean Air Act [25]. When the toxicity of the newer formulation was examined after the epidemic [26], it was found to be considerably more toxic than the 
earlier preparation. Common to several of the human cases, there was an apparent disregard of the manufacturer's warning printed on the spray can, as most patients had vaporized the spray in tiny, cramped and poorly ventilated rooms, or were smoking at the same time [24]. Since the disease was self-limited and no biopsies were taken, it is unclear whether the infiltrates represented pulmonary oedema, interstitial lung disease, the BOOP/OP complex, or any combination thereof.

2) An outbreak of desquamative interstitial pneumonitis has been reported on in five out of 88 patients employed in a textile plant [27]. The prognosis was good, and there were no deaths. Although there was exposure to several agents, including dyes and glues, the authors speculated that the disease resulted from exposure to the aflatoxinproducing mold Fusarium sp. [27]. However, this could not be substantiated, because another outbreak developed in a similar factory in Rhode Island, where evidence for chronic diffuse interstitial lung disease was found in seven out of 165 workers in the nylon flocking industry [28]. There were only modest concentrations of fungal spores in the air [28]. Of the seven index cases, five had nonspecific interstitial pneumonitis, one had BOOP and one had eosinophilic pneumonia [28]. The outbreak was linked to inhalation of nylon fibres, and the disease was given the name "flock-workers lung" [28].

Very few cases of authentic BOOP have been related to airborne agents, and single massive exposure to $\mathrm{NO}_{2}$, chlorine, cocaine and, perhaps, cadmium emerge as possible causes in experimental animals [29, 30] and humans $[19,31]$, respectively. One case of BOOP has been reported following inhalation of a dust cloud from Penicillium janthillenum, that covered mouldy orange juice [32]. The patient made a full recovery.

A spontaneous outbreak of self-limited OP with associated cholestasis has been reported on in the UK and, although no aetiological agent was identified, the seasonal nature of the illness suggested the involvement of an inhaled agent [33].

The patients described by Romero et al. [1] clearly differ from those mentioned above, because: the lung disease was consistently organizing pneumonia; there was associated nose bleeding; it developed after prolonged exposure to the fumes ( $9.1 \pm 3.5$ months on average); the prognosis was variable; and a sizable fraction of patients developed chronic lung fibrosis [1, 34].

Regarding the latter aspect, the cases described by ROMERO et al. [1] resemble severe BOOP cases [4, 35], as reported in the context of rheumatoid arthritis [36], polymyositis [37], scleroderma [38] or following exposure to such drugs as penicillamine [38] or nitrofurantoin [37]. The lack of response to steroids or cyclophosphamide in these cases, as well as in some of those described by ROMERO et al. [1] is intriguing, and contrasts with classic BOOP $[3-5,39]$.

\section{Research into the causal mechanism(s) in relation to the Ardystil syndrome}

The Acramin F system is a three-component, water-based printing mixture manufactured by Bayer AG (Germany). Acramin $\mathrm{F}$ has been extensively used for dying textiles since the early 1950s, with no respiratory or other adverse effect. It is usually applied with a brush or sponge, or in screen printing. However, in the Spanish factories, the Acramin-containing paint was sprayed with air guns. This generated high levels of a respirable aerosol in the air of cramped workshops and, as mentioned by several authors $[2,6]$, the hygiene conditions were poor.

Although the epidemiological evidence linking the disease in humans to the air-spraying of a mixture of Acramin FWN and a solvent was strong from the beginning, it must be pointed out that no experimental evidence or explanation was available at that time [2]. As a consequence, the outbreak of pulmonary toxicity was totally unexpected.

Acramin FWN is a polyamide-amine which, like most polymers, has a very low acute oral and inhalational toxicity, with rat median lethal dose $($ LD50) $>2,000 \mathrm{mg} \cdot \mathrm{kg}$ body weight ${ }^{-1}$, and median lethal concentration (LC50) (4 h) $>2,149 \mathrm{mg} \cdot \mathrm{m}^{-3}$. In rabbits, Acramin FWN is not irritating to the eyes or skin (Material Safety Data Sheet and data on file from the manufacturer). The other Acramin species, Acramin FWR, is a polyurea, which has also demonstrated very low oral and dermal toxicity and no irritant potential in appropriate assays (Manufacturer's data). However, none of the compounds that are part of the Acra-min F family were ever intended to be air-sprayed and, thus, they were not supposed to be present in aerosol form in any workplace. Accordingly, no toxicological data had been obtained as regards their possible airway or lung paren-chymal toxicity via inhalation. Had they been asked, we believe that most toxicologists would probably have concluded that, since polyureas and polyamideamines are inert polymers, the likelihood of toxicity from exposure to Acramins should be low.

Results of recent animal experiments have, however, shown that this is not true. Intratracheal instillation of a single dose of Acramin FWR or FWN resulted in a marked and surprising degree of lung damage in hamsters [40]. An inhalation toxicity study of respirable aerosol of Acramin FWR or FWN in rats (concentrations of 50 or $250 \mathrm{mg} \cdot \mathrm{m}^{-3} \times 6 \mathrm{~h} \cdot$ day $^{-1}, 5$ days $\cdot$ week $^{-1}$ for two consecutive weeks) led to substantial pulmonary damage and this was ultimately followed by fibrosis of the lung [41]. It should be noted that the concentrations examined in that study are unlikely to be encountered in the workplace, where total level of paint (of which Acramin is only a part) amounted to $10 \mathrm{mg} \cdot \mathrm{m}^{-3}$ in one factory [2]. The experimental effects of concentrations likely to be found in the workplace are currently unknown, and studies in that area are clearly needed.

Subsequent in vitro experiments, using rat and human alveolar macrophages, as well as primary cultures of type II alveolar cells also indicated that Acramin compounds are cytotoxic [42]. Although both the concentration and mode of administration differed in these experimental studies, as compared to conditions in the factories, they give support to the notion that Acramin-containing paints can damage the lung. In no way, however, does it emerge from either in vivo or in vitro studies that the more recently introduced Acramin FWN exhibits higher toxicity than Acramin FWR. In fact, the converse proved to be the case in the subacute inhalation experiments [41]. It is conceivable that the change in formulation that accompanied the substitution of FWR by FWN altered the aerosol properties of the paint, but this remains to be investigated. Other avenues to be explored include the possible concomitant 
utilization of other agents such as cross-linking compounds [7], but so far, there is no consistent evidence in favour of this hypothesis. Although neuropsychological effects were reported [43], which suggests exposure to elevated levels of organic solvents, a pivotal role for solvents, or their toxic thermal degradation products (e.g. phosgene), appears unlikely.

\section{Conclusion}

Many questions are raised by the outbreak described by Moya et al. [2] and Romero et al. [1]. The exact reactive chemical species and mechanism(s) responsible for the disease are unclear. The precise sequence of events leading to organizing pneumonia are unclear as well, in particular whether organizing pneumonia was a de novo process, or resulted from the late organization of pulmonary oedema, as described following exposure to $\mathrm{Cl}_{2}, \mathrm{NO}_{2}$, or cadmium fumes $[17,19,29]$, is unknown. The lack of response to steroids in some cases, as opposed to classic bronchiolitis obliterans organizing pneumonia, is disturbing as well.

This outbreak also clearly points to the need to improve the protection of workers exposed to mists of uncertain toxicity or unproven inoccuity. Efforts should also be directed to the public, as some domestic sprays may prove hazardous. In this connection, there is a need to test reformulated sprays before their commercial release, as suggested by recent epidemics of severe lung disease after exposure to reformulated sprays [25, 26, 44], which ultimately proved toxic when examined later in experimental animals [26].

The Spanish outbreak [1] also reminds us, as pulmonologists, that novel respiratory diseases, and causes for them, may emerge at any time. Typical examples of novel environmentally-related illnesses include: the toxic oil syndrome [45]; the L-tryptophan syndrome [46]; more recently, bronchiolitis obliterans caused by ingestion of the vegetable food supplement Sauropus androgynus [47-49] or by fumes from stoves [50, 51]; and pulmonary infiltrates caused by the ingestion of medicinal herbs [52-54].

Accordingly, a careful clinical watch should be de rigueur in pulmonology, a discipline in which newer infectious [55, 56], drug-induced [57], idiopathic [58-61], and environment/occupation-related diseases $[1,2,27]$ may unexpectedly increase at any given time. We are pleased that the Journal is an arena where these novel diseases are being described.

\section{References}

1. Romero S, Hernandez L, Gil J, Aranda I, Martin C, Sanchez-Paya J. Organizing pneumonia in textile printing workers. A clinical description. Eur Respir J 1998; 11: 265-271.

2. Moya C, Anto JM, Newman-Taylor AJ, et al. Outbreak of organising pneumonia in textile printing sprayers. Lancet 1994; 344: 498-502.

3. Epler GR, Colby TV, McLoud TC, Carrington CB, Gaensler EA. Bronchiolitis obliterans organizing pneumonia. N Engl J Med 1985; 312: 152-158.

4. Cordier JF, Loire R, Brune J. Idiopathic bronchiolitis obliterans organizing pneumonia. Chest 1989; 96: 9991004.
5. Boots RJ, Mowat P, McEvoy JDS, Le Fevre I. Bronchiolitis obliterans organising pneumonia: a clinical and radiological review. Aust NZ J Med 1995; 25: 140-145.

6. Wickman R. Spanish paint disaster causes lung fibrosis. Br Med J 1993; 306: 416-417.

7. Sanz P, Prat A. Toxicity in textile air-brushing in Spain. Lancet 1993; 342: 240.

8. Ould Kadi F, Mohammed-Brahim B, Fyad A, Lellou S, Nemery B. Outbreak of pulmonary disease in textile dye sprayers in Algeria. Lancet 1994; 344: 962-963.

9. Charan NB, Myers CG, Lakshminarayan S, Spencer TM. Pulmonary injuries associated with acute sulfur dioxide inhalation. Am Rev Respir Dis 1979; 119: 555-560.

10. Yockey CC, Eden BM, Byrd RB. The McConnell missile accident. Clinical spectrum of nitrogen dioxide exposure. JAMA 1980; 244: 1221-1223.

11. Douglas WW, Hepper NGG, Colby TV. Silo-filler's disease. Mayo Clin Proc 1989; 64: 291-304.

12. Sjögren B, Plato N, Alexandersson R, Eklund A, Falkenberg C. Pulmonary reactions caused by welding-induced decomposed trichloroethylene. Chest 1991; 99: 237-238.

13. White CS, Templeton PA. Chemical pneumonitis. Radiol Clin North Am 1992; 30: 1231-1243.

14. Das R, Blanc PD. Chlorine gas exposure and the lung: a review. Toxicol Industr Health 1993; 9: 439-455.

15. Coggon D, Inskip H, Winter P, Pannett B. Lobar pneumonia: an occupational disease in welders. Lancet 1994; 344: 41-43.

16. Douglas WW, Colby TV. Fume-related bronchiolitis obliterans. In: Epler GR, ed. Diseases of the Bronchioles. New York, Raven Press, Ltd, 1994; pp. 187-213.

17. Fernandez MA, Sanz P, Palomar M, Serra J, Gadea E. Fatal chemical pneumonitis due to cadmium fumes. Occup Med 1996; 46: 372-373.

18. Townshend RH. Acute cadmium pneumonitis: a 17 year follow-up. Br J Indust Med 1982; 39: 411-412.

19. Schwartz DA. Acute inhalational injury. State Art Rev Occup Med 1987; 2: 297-318.

20. Yates DH, Goldman KP. Acute cadmium poisoning in a foreman plater welder. Br J Indust Med 1990; 47: 429_ 431.

21. Nemery B. Late consequences of accidental exposure to inhaled irritants: RADS and the Bhopal disaster. Eur Respir J 1996; 9: 1973-1976.

22. Cullinan P, Acquilla S, Dhara VR. Respiratory morbidity 10 years after the Union Carbide gas leak at Bhopal: a cross sectional survey. Br Med J 1997; 314: 338-342.

23. Kelly KJ, Ruffing R. Acute eosinophilic pneumonia following intentional inhalation of Sctotchguard. Ann Allergy 1993; 71: 358-361.

24. Burkhart KK, Britt A, Petrini G, O'Donnell S, Donovan JW. Pulmonary toxicity following exposure to an aerosolized leather protector. Clin Toxicol 1996; 34: 21-24.

25. Smilkstein MJ, Burton BT, Keene W, Barnett M, et al. Acute respiratory illness linked to case of aerosol leather conditioner - Oregon December 1992. MMWR 1993; 41: 965-967.

26. Hubbs AF, Castranova V, Ma JYC, et al. Acute lung injury induced by a commercial leather conditioner. Toxicol Appl Pharmacol 1997; 143: 37-46.

27. Lougheed MD, Roos JP, Waddell WR, Munt PW. Desquamative interstitial pneumonitis and diffuse alveolar damage in textile workers. Potential role of mycotoxins. Chest 1995; 108: 1196-1200.

28. Kern DG, Durand KTH, Crausman RS, et al. Chronic interstitial lung disease in nylon flocking industry workers. Rhode Island, 1992-1996. MMWR 1997; 46: 897-901. 
29. Winternitz MC. Collected studies on the pathology of war gas poisoning. New Haven, CT, Yale University Press; 1920.

30. Damiano VV, Cherian PV, Frankel FR, et al. Intraluminal fibrosis induced by lobar instillation of $\mathrm{CdCl}_{2}$ into the rat lung. Am J Pathol 1990; 137: 883-892.

31. Patel RC, Dutta D, Schonfeld SA. Free-base cocaine use associated with bronchiolitis obliterans organizing pneumonia. Ann Intern Med 1987; 107: 186-187.

32. Bates C, Read RC, Morice AH. A malicious mould. Lancet 1997; i: 1598.

33. Spiteri MA, Klenerman P, Sheppard MN, Padley S, Clark TJK, Newman-Taylor A. Seasonal cryptogenic organising pneumonia with biochemical cholestasis: a new clinical entity. Lancet 1992; 340: 281-284.

34. Solé A, Cordero PJ, Morales P, Martinez ME, Vera F, Moya C. Epidemic outbreak of interstitial lung disease in aerographics textile workers - "Ardystil syndrome": a first year follow-up. Thorax 1996; 51: 94-95.

35. Nizami IY, Kissner DG, Vissher DW, Dubaybo BA. Idiopathic bronchiolitis obliterans with organizing pneumonia. An acute and life-threatening syndrome. Chest 1995; 108: 271-277.

36. Rees JH, Woodhead MA, Sheppard MN, du Bois RM. Rheumatoid arthritis and cryptogenic organising pneumonitis. Respir Med 1991; 85: 243-246.

37. Cohen AJ, King TE Jr, Downey GP. Rapidly progressive bronchiolitis obliterans with organizing pneumonia. Am J Respir Crit Care Med 1994; 149: 1670-1675.

38. Muir TE, Tazelaar HD, Colby TV, Myers JL. Organizing diffuse alveolar damage associated with progressive systemic sclerosis. Mayo Clin Proc 1997; 72: 639-642.

39. Lohr RH, Boland BJ, Douglas WW, et al. Organizing pneumonia: features and prognosis of cryptogenic, secondary, and focal variants. Arch Intern Med 1997; 157: 1323-1329.

40. Clottens FL, Verbeken EK, Demedts M, Nemery B. Pulmonary toxicity of components of textile paint linked to the Ardystil syndrome: intratracheal administration in hamsters. Occup Environ Med 1997; 54: 376-387.

41. Nemery B, Clottens FL, Hoet PHM, Pauluhn J, Mohr U. Toxicological research into the etiology of the Ardystil syndrome. In: Chiyotani K, ed. 9th International Conference on Occupational Respiratory Diseases. Kyoto, Elsevier Excerpta Medica; 1998; in press.

42. Hoet PHM, Gilissen L, Leyva M, Demedts M, Nemery B. Toxicity of polycationic paint components linked to the "Ardystil syndrome" in rat and human type II pneumocytes and alveolar macrophages. (Abstract). Eur Respir J 1997; 10: Suppl. 25, 43S-44S.

43. Solé A, Cordero P. Sìndrome Ardystil. Med Clin (Barcelona) 1995; 105: 295-297.

44. Kulig K, Brent J, Messenger T, et al. Severe acute respiratory distress linked to use of shoe sprays. Colorado, November 1993. MMWR 1993; 42: 885-887.
45. Alonso-Ruiz A, Calabozo M, Perez-Ruiz F, Mancebo L. Toxic oil syndrome. A long-term follow-up of a cohort of 332 patients. Medicine (Baltimore) 1993; 72: 285-295.

46. Kilbourne EM, Philen RM, Kamb ML, Falk H. Tryptophan produced by Showa Denko and epidemic eosinophilia-myalgia syndrome. J Rheumatol 1996; 23: 81-88.

47. Roggli VL, Chiang A. Constrictive bronchiolitis obliterans in Sauropus androgynus poisoning. J Toxicol - Clin Toxicol 1996; 34: 525-526.

48. Wu CL, Hsu WH, Chiang CD, et al. Lung injury related to consuming Sauropus androgynus vegetable. J Toxicol Clin Toxicol 1997; 35: 241-248.

49. Higenbottam TW. Bronchiolitis obliterans following the ingestion of an Asian shrub leaf. Thorax 1997; 52: S68S72.

50. Janigan DT, Kilp T, Michael R, McCleave JJ. Bronchiolitis obliterans in a man who used his wood-burning stove to burn synthetic construction materials. Can Med Assoc $J$ 1997; 156: 1171-1173.

51. Hogg JC. Bronchiolitis obliterans and wood-burning stoves. Can Med Assoc J 1997; 156: 1147-1148.

52. Ishizaki T, Sasaki F, Ameshima S, et al. Pneumonitis during interferon and/or herbal drug therapy in patients with chronic active hepatitis. Eur Respir J 1996; 9: 26912696.

53. Tojima H, Yamazaki T, Tokudome T. Two cases of pneumonia caused by Sho-saiko-to. Nippon Kyobu Shikkan Gakkai Zasshi 1996; 34: 904-910.

54. Mizushima Y, Oosaki R, Kobayashi M. Clinical features of pneumonitis induced by herbal drugs. Phytother Res 1997; 11: 295-298.

55. Zaki SR, Shieh WJ. Leptospirosis associated with outbreak of acute febrile illness and pulmonary haemorrhage, Nicaragua, 1995. Lancet 1996; 347: 535-536.

56. Levis S, Rowe JE, Morzunov S, Enria DA, Stjeor S. New hantaviruses causing hantavirus pulmonary syndrome in central Argentina. Lancet 1997; 349: 998-999.

57. Foucher P, Biour M, Blayac JP, et al. Drugs that may injure the respiratory system. Eur Respir J 1997; 10: 265-279.

58. Riemer H, Hainz R, Stain C, et al. Severe pulmonary hypertension reversed by antibiotics in a patient with Whipple's disease. Thorax 1997; 52: 1014-1015.

59. Jain S, Kahn CB, Pella J, Myers JR. Noncardiogenic pulmonary edema in a patient with diabetic ketoacidosis. Diabetes Care 1997; 20: 1922-1923.

60. Saito K, Morita M, Enomoto K. Bronchiolitis obliterans with pemphigus vulgaris and Castleman's disease of hyaline-vascular type: an autopsy case analyzed by computer-aided 3-D reconstruction of the airway lesions. Hum Pathol 1997; 28: 1310-1312.

61. Drent M, Peters FPJ, Jacobs JA, van de Brink KIM, Wagenaar SS, Wouters EFM. Pulmonary infiltration associated with myelodysplasia. Ann Oncol 1997; 8: 905-909. 